\title{
EVALUATION OF NATIONAL CURRICULUM AND IMPLEMENTATION IN JUNIOR VOCATIONAL EDUCATION
}

\author{
Jittie Brandsma, Alfons ten Brummelhuis and Tjeerd Plomp \\ Centre for Applied Educational Research, University of Twente, P.O. Box 217, \\ 7500 AE Enschade, The Netherlands
}

In the early seventies, junior technical vocational education in the Netherlands was fundamentally restructured as a consequence of a change in the national policy towards junior vocational education. This restructuring can be characterized as:

- generalization - an increasing amount of time spent on non-vocational subjects, less specialization and greater attention to the personal development of pupils;

- broadening - integration of several specialist but interrelated streams; and

- harmonizing - creation of more coherence and unity in the goals and objectives of different types of junior vocational education (Kayzel \& Van Wel, 1984).

Due to these changes the number of different technical streams within junior technical vocational education decreased from twenty-seven to seven. At the time the policy change was implemented in practice, there were no curricula available for the seven new streams in junior technical vocational education. Thus in the years following, several curriculum innovation projects were initiated in order to provide them. Three of these innovation projects have been evaluated in the research here presented. It concerns the curriculum innovation projects on electrotechnics, installation technics and mechanical technics. Two of these innovation projects were started in the late seventies and ended in the early eighties. The third project lasted from 1981 until $1986^{1}$. 
The projects had a common aim: realizing educational change through developing a model curriculum, to be defined as a document, that included the objectives, contents and the organization of the instruction within a certain school or school type. During the progress of the projects, each of the projects addressed the development of the model curriculum plus the development of exemplary instructional materials and a formulation of proposals for the equipment needed for teaching the new curriculum.

In this paper we present the results of the comparative analysis of these three curriculum innovation projects ${ }^{2}$. The purpose of the study was to provide policy makers with empirical information on the basis of which they could improve their policy with regard to curriculum development in this education sector. The research question to be answered is: which factors (negative as well as positive) can be identified that influence the degree of success of these curriculum innovation projects? Within the projects we will make a distinction between the curriculum development process on the one hand and the implementation process on the other hand.

Before looking at the results of the study, it is necessary, for a clear comprehension of the context and proceeding of these projects, to give a brief sketch of the Dutch educational support system.

The Dutch Educational Support System

Within the scope of this paper the three most important national educational support institutions are: the National Institute for Curriculum Development (SLO), the National Innovation Centres (LPC) and the National Institute for Educational Measurement (CITO).

The main aims and responsibilities of the National Institute for Curriculum Development (SLO) are the development of model curricula and model teaching kits for all educational organizations and institutions. These tasks are carried out both in subject-oriented projects and in national innovation projects (Jozefzoon et al., 1986). The curriculum materials developed by the SLO have primarily an exemplary character. The development of instructional materials, such as teaching methods and school books, is delegated to educational publishers. 
The major tasks of the National Centres (LPC) concern the participation in the innovation projects (both small and large-scale national projects), in which the LPC fulfil support and co-ordination functions. Direct support is also given to secondary schools. The main task of the National Institute for Educational Measurement is, as its name already reveals, the construction of tests for different school types (Jozefzoon et al., 1986).

\section{Conceptual Framework and Design}

As mentioned above, we distinguish two phases within the curriculum innovation projects: the curriculum development phase and the implementation phase. These phases are presented in Figure 1.

development phase

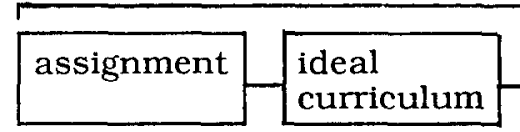

adoption and implementation phase

Figure 1: The Curriculum Development Phase

Each project started with an assignment which included guidelines for the curriculum to be developed as well as the development process (in more or less elaborated form). We described the ideal curriculum as the ideas and beliefs about the model curriculum and/or the development process, which have been formulated and mutually accepted (by the participants) at the beginning of the project. The formal curriculum is, in this study, conceived as the model curriculum (as defined earlier) together with the exemplary instructional materials. The last stage, the operational curriculum, can be conceived as the instructional processes that take place in the classroom ${ }^{3}$.

The curriculum development phase starts with the provision of the assignment and ends when the formal curriculum is ready. The implementation phase reflects the transition from the formal curriculum into the operational curriculum. 
Based on the distinction between the two phases in the course of curriculum innovation projects, the general research question has been further operationalized and two main research questions have been distinguished:

- which factors (positive as well as negative) have, in each of the projects, influenced the development of a formal curriculum? and, - which factors (positive as well as negative) have influenced the dissemination and implementation of the formal curriculum?

These questions are reflected in figure 2, which presents the framework for both the data collection and analysis.

In order to answer the research questions it was necessary to reconstruct the development process of the formal curriculum as well as to examine the extent to which schools had the model curriculum, the exemplary instructional materials and the new equipment at their disposal, and also used these curriculum materials. Use has been made of three complementary research methods: document analysis, survey and interviews.

development phase adoption and implementation phase

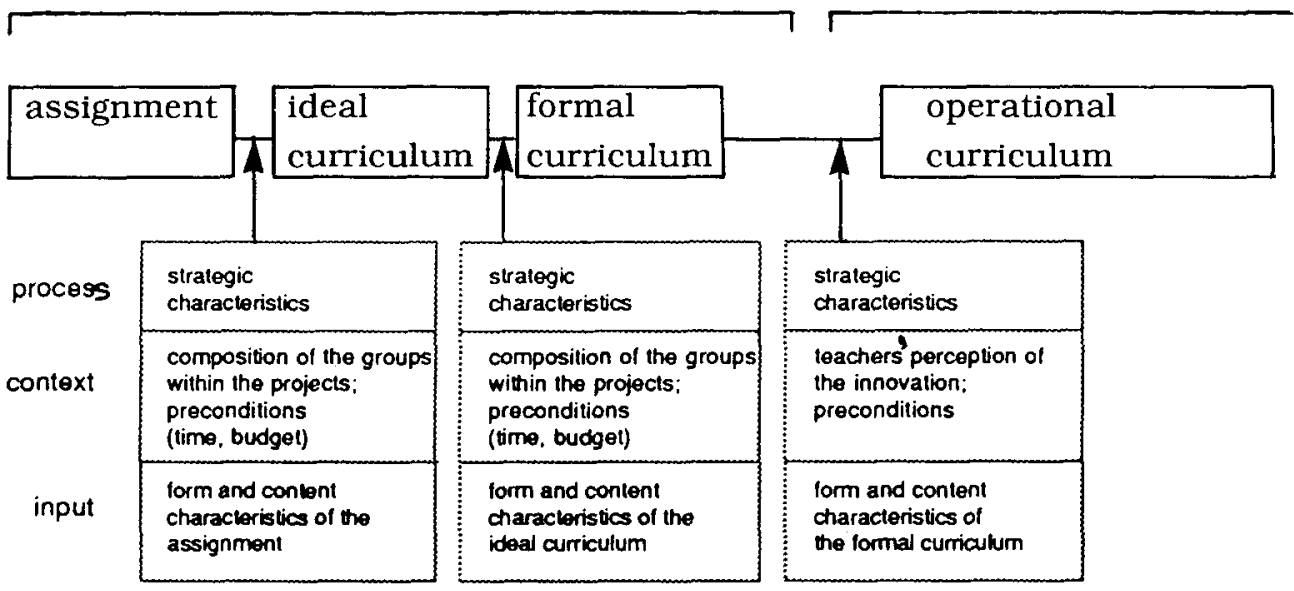

Figure 2: Development Phases: Specification of Characteristics

By means of document analysis a reconstruction was made of the actual course of the curriculum development process within the three 
projects. Over 3,500 textual fragments derived from different project documents were encoded, following a systematic procedure based on Miles and Huberman (1984). The processing of these data was done by computer. The framework for the data-processing was based on the variables included in the comparative evaluation. After storage of all the textual fragments, selections of fragments assigned to a specific variable were made for each project. Following this procedure a systematic description was made of each project. These descriptions formed the starting point for the comparative evaluation. A special procedure for monitoring the interrater reliability was developed (Weesie \& Ten Bummelhuis, 1986). The interrater reliability of this encoding procedure was satisfactory (lowest Kappa coefficient 0.70 , highest Kappa coefficient 0.93). The Kappa coefficient was calculated after Scott's formula (Scott, 1955).

In the survey information was gathered about the degree of dissemination and use of the model curriculum, exemplary instructional materials and the new equipment. A stratified sample of 445 schools was drawn out of a population of 690 schools, and these 445 were approached with a questionnaire; the response percentage was $75 \%$.

In the interviews information was gathered on the teachers' motives for using the model curriculum and the accompanying curricular materials as well as the problems faced trying to implement the innovations. In total twenty three schools were approached for an interview. The selection of these respondents was based on the results of the survey, according to which all responding schools were classified into twelve categories that were constructed by means of the following criteria:

- whether or not the model curriculum was being used;

- whether or not the exemplary instructional materials and equipment were at the school's disposal.

The Curriculum Development Phase

With regard to the curriculum development process we will elaborate on the assignment given to the development agent, the participants within the projects and their tasks, and the elements of the development strategy and the model curriculum. 
The assignment

Regarding the assignment, a distinction can be made between product-indications and process or context-indications. Productindications can be defined as indications specifying certain elements of the formal curriculum that has to be developed. Process or context indications can be defined as statements that establish certain elements of the curriculum innovation process or the context in which the projects have to proceed, such as the strategies to be used, the participants in the projects and the financial facilities. Table 1 presents an overview of the indications included in the assignment for each of the three projects.

Table 1: Indications Included in the Assignment

\begin{tabular}{|c|c|c|c|}
\hline \multicolumn{4}{|l|}{ PROCES AND CONTEXT } \\
\hline \multicolumn{4}{|l|}{ INDICATIONS } \\
\hline length of project & - & - & $x$ \\
\hline participants & - & $\mathrm{x}$ & $x$ \\
\hline organization structure & - & - & $x$ \\
\hline tasks of participants & $x$ & - & - \\
\hline \multicolumn{4}{|l|}{ PRODUCT INDICATIONS } \\
\hline platforms & - & $x$ & $x$ \\
\hline objectives & $x$ & - & $x$ \\
\hline student entry behaviors & $x$ & - & - \\
\hline instructional materials & $x$ & - & - \\
\hline \multicolumn{4}{|l|}{ learner experiences/- } \\
\hline teaching strategies & $x$ & $x$ & - \\
\hline content & $x$ & $x$ & - \\
\hline assesment tools/procedures & $x$ & - & - \\
\hline time & $x$ & $x$ & $x$ \\
\hline \multicolumn{4}{|l|}{ commentary: } \\
\hline \multicolumn{4}{|c|}{$\mathrm{ET}=$ project electrotechnics; } \\
\hline \multirow{2}{*}{\multicolumn{4}{|c|}{$\begin{array}{l}\mathrm{IT}=\text { project installation technics; } \\
\mathrm{MT}=\text { project mechanical technics; }\end{array}$}} \\
\hline & & & \\
\hline
\end{tabular}


The overview shows some considerable differences between the three assignments. The assignments for the projects on electrotechnics and installation technics (which have been formulated by the development institutions), include hardly any indications with regard to the organization of the curriculum development process. The assignment for the project on mechanical technics that has been formulated by the Department of Education and Science (DoE), is more detailed. The DoE established a committee with the task of formulating a detailed plan of action for the project. The DoE also gave indications about the length of the project, the members of the committee and (partly) the organizational structure for the project. Since the committee would be responsible for the project's plan of action there were only a few product indications included in the assignment.

The product indication 4 in the other two assignments vary substantially. The indications for the project on electrotechnics give a rather detailed description of both the development strategies and the curricular products that aim to be the result of these strategies. The product indications for the project on installation technics on the other hand cover only some of the curriculum dimensions and are formulated in broad and general terms. None of the assignments gives indications regarding budgetary limitations ${ }^{5}$.

\section{Participants}

In each of the projects three groups can be distinguished: an advisory committee, a coordination team and an executive team.

The advisory committee contains representatives with the following background: the schools inspectorate, the school management, teachers, teacher training institutions and participating institutions from the educational support system 6 . In two of the projects representatives of organizations from the apprentice system and business and industry were members of the advisory committee. The national government the DoE and the Department of Labour) was represented in only one of the projects. The actual tasks of the advisory committee consisted in keeping up with the progress of the project and advising the co-ordination and executive team. 
In each project the executive team included the representatives of participating educational support institutions and teachers of the technical stream that was involved in the project. These were teachers from a few schools, which were most actively involved in the curriculum development process (from four schools in one project and up to six schools in the other two projects). The above-mentioned representatives of the educational support institutions also formed the coordination team.

The most important tasks of the executive team (especially the teachers) were their contributions to the formation of objectives and the development of instructional materials ${ }^{7}$. The executive teams in the installation technics and mechanical technics projects also contributed to the development of proposals for the modernization of the equipment. The executive team in the latter project formulated further suggestions for the training of teachers. The coordination team had an important position in each of the projects; their tasks concerned the planning and monitoring of the project, the preparation and implementation of activities and the training of directly-involved teachers with regard to their tasks in the project.

Although there was a certain division of tasks within each of the three projects, the demarcation between the tasks and responsibilities of each group was not always very clear. Besides this it seems that none of the advisory committees has fulfilled tasks with regard to the monitoring of the progress or the decision-making process.

Planning and realization of activities

As stated before, each project aimed at realizing educational change through the development and dissemination of a model curriculum. Although the aim of the projects was similar, they varied in the organization and realization of their development strategies. Table 2 gives an overview of the different activities which have been undertaken in each of the three projects during the curriculum development process as well as the relationship between planned and realized activities.

Comparing the development activities of the three projects there are, besides the expected differences, also similarities. Both the project on electrotechnics and the project on mechanical technics started the curriculum development process with a rather detailed plan. In the 
project on installation technics on the other hand, only the development of a model curriculum was foreseen in the assignment (as formulated by the development institution), without much further specification of the content of this document. After the completion of this model curriculum (including objectives) it was the coordination team supported by the executive team that proposed not to stop the project but to continue with the development of instructional materials as well as with proposals for the renewal of equipment - elements that were not mentioned in the assignment. The principle behind this decision was the idea that educational change cannot be realized by introducing only a model curriculum, but also demands the availability of instructional materials and the necessary equipment as well as the training of teachers.

Table 2: Planned and Realized Development Activities

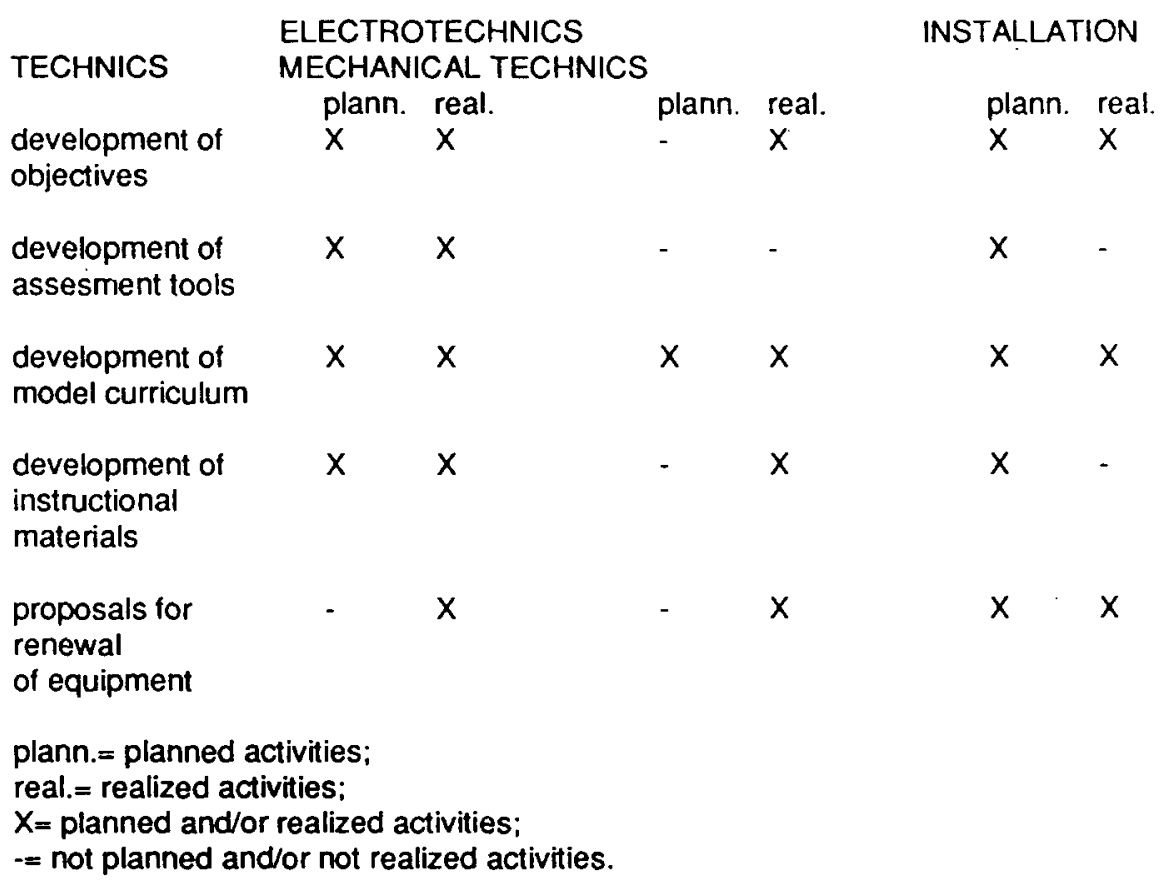


In the project on mechanical technics it appeared not to be possible to develop instructional materials and assessment tools within the given project time. This lack of time was partly caused by vagueness in the division of tasks and responsibilities within the project. However, it is necessary to remark that the instructional materials, which have been developed in the other two projects, are not ready-made, usable products. These materials need further elaboration before they can be used in the classroom. The necessary time for this elaboration has been lacking in the projects $^{8}$. With regard to this aspect of the curriculum development strategy the question can be posed, whether the choice to have these materials developed by teachers was the most effective one, since the expertise of teachers primarily concerns teaching, and in their initial training no attention is given to curriculum development. If it is decided to have instructional materials developed by teachers, this at least demands a substantial amount of training.

Although some proposals were developed for the renewal of equipment within each of the projects, the final formulation of such proposals did not belong to the tasks of the projects. These final proposals were drawn up by a committee of the DoE. Only one project (installation technics) was directly represented in this committee. The other two projects had to keep up with the committees' decisions through less direct contacts. Problems with regard to the attuning of the development of instructional materials, training and the choice of new equipment were partly caused by this situation. The fact that the choice of new equipment was made as the projects were coming to an end (and the model curriculum and the exemplary instructional materials were developed), was also a factor in these problems.

The model curriculum

Our analysis of the model curriculum was directed at external characteristics (such as: number of pages, lay-out, illustrations, etc.) as well as instructional characteristics. Here we will concentrate on the results of the analysis of instructional characteristics, which was based on the earlier-mentioned dimensions of curriculum innovation (Leithwood, 1981). In combination with these curriculum dimensions, use is made of three approaches for the analysis of these characteristics: 
- the degree of elaboration;

- the nature of the description;

- the reforming components (Meesterberend-Harms, 1984).

The first approach considers the extent to which the description of the curriculum dimensions is elaborated and detailed; a detailed and categorized description of a curriculum dimension is defined as "concrete". If the description of a curriculum dimension is stated in general and broad terms, it is defined as "general".

The second approach refers to the distinction between 'fidelity' and the 'mutual adaptation' approach to implementation (Fullan \& Pomfret, 1979; Fullan, 1985). The mutual adaptation approach assumes that guidelines with regard to the use and implementation of a curriculum cannot be prescriptive. The different groups of users have to decide what is most appropriate in their situation and have to adapt the curriculum according to this. Within the fidelity approach, implementation assumes a faithful use of the new curriculum; that is to say, use in practice has to correspond with the intentions of the developers of the curriculum. Therefore guidelines for use and implementation are of a prescriptive character. The analysis of the instructional characteristics in terms of 'nature of description' refers to the extent to which a description of a curriculum dimension gives a user of the model curriculum the opportunity to adapt it to his/her own situation. Descriptions that do give this opportunity are defined as "recommending". If this opportunity is not available the description is defined as "prescriptive". During the analysis it appeared that with regard to some dimensions in the model curricula it could not be decided whether the description was prescriptive or recommending. These descriptions were stated in such general and broad terms, that no more than a qualification "informing" could be applied to it. The third and last approach refers to the extent to which a curriculum dimension includes innovative components.

Table 3 gives an overview of the instructional characteristics of the model curricula that have been developed within the three projects. 
Table 3. Overview of the Didactical Characteristics of the Model Curriculum

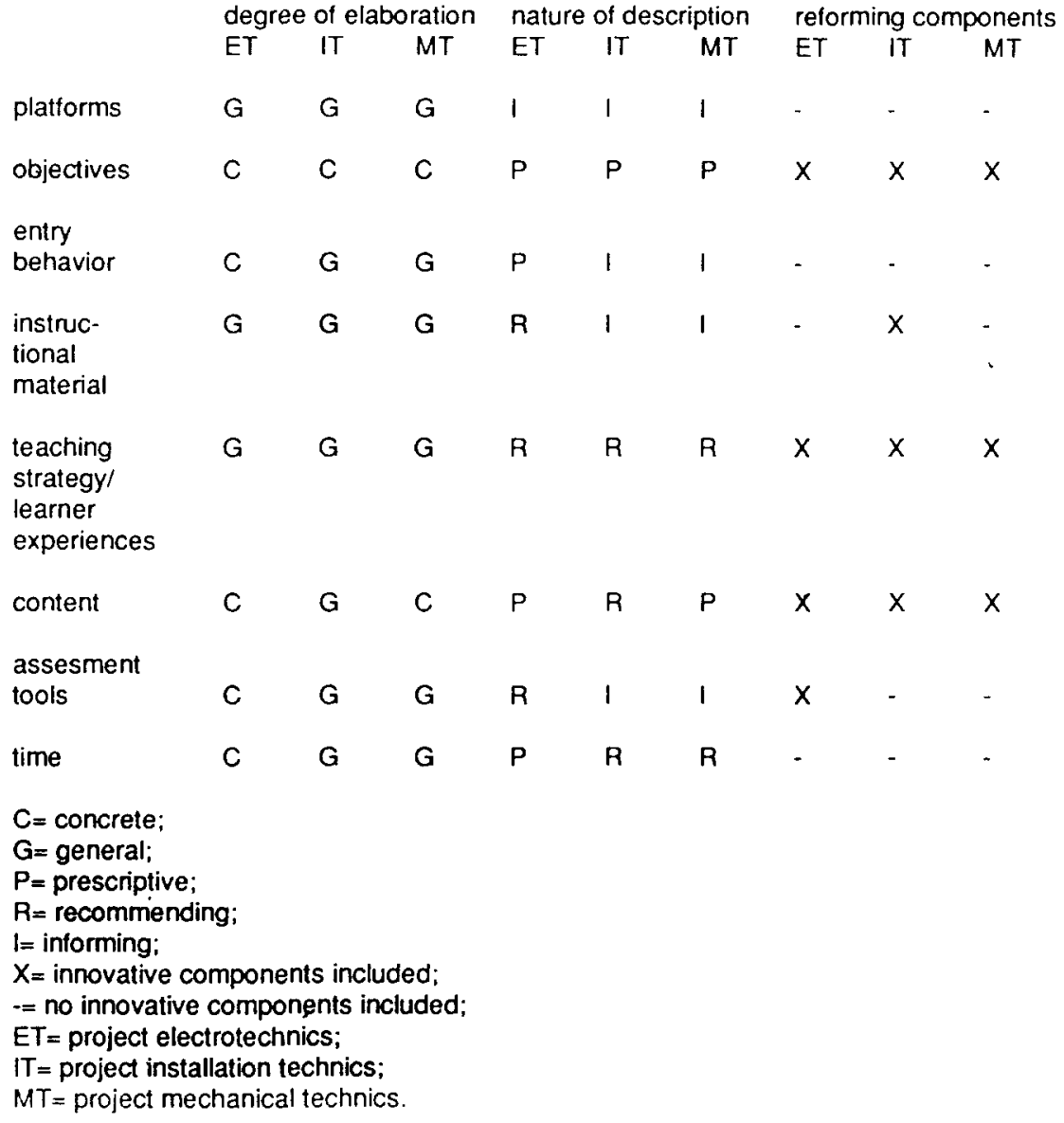

The comparison of the three model curricula shows that attention is paid to all of the distinguished curriculum dimensions in each of them. However, the degree of elaboration as well as the nature of the description vary strongly between the three documents. The model curriculum for electrotechnics is the most elaborate and also the most prescriptive. The innovative components that are included in the curricula concern primarily the objectives, content and teaching strategies/learner experiences. Next to these, the projects have also proposed subject matter changes, related to the implementation of new equipment. These changes are not mentioned in the model curricula ${ }^{9}$. 
The development of a model curriculum was one of the planned and realized elements of the development strategy that was described in the preceding section. The model curriculum for electrotechnics was disseminated piece by piece over four years. The intention to adjust it after testing in the schools, could not be realized due to lack of time.

The development of a model curriculum for installation technics formed the first phase of this project. After the completion of this document the project launched into the development of instructional materials and proposals for the renewal of equipment. These elements of the curriculum development strategy do not reflect the model curriculum. In the project on mechanical technics the plan was to develop a model curriculum in the first phase of the project. In the end the document was completed just before the project was finished.

\section{The Implementation Phase}

The curriculum development process in the three projects has resulted in the following products, which are now more or less completed:

- a model curriculum

- a first draft of instructional material (excluding mechanical technics);

- $\quad$ proposals for the renewal of equipment

In the implementation phase these products were disseminated and implemented in the educational field.

With regard to the dissemination and implementation of the curriculum materials and proposed educational changes, several activities have been undertaken. These activities have been executed during the curriculum development process as well as after the development process (and the project) was concluded. The implementation strategy in the three projects has included three types of activities:

- information;

- training;

- purchase and dissemination of new equipment 
The information was primarily meant to acquaint the schools with the proceeding of the project and the proposals for educational innovations as well as to support the adoption of these innovations. The information was given by means of information meetings (regionally organized) and an information bulletin.

The training courses included both didactical and technical training. The development and organization of these courses were not part of the projects, but were the responsibility of the teacher-training institutions. In two projects (installation technics and mechanical technics) the DoE intervened by giving an assignment to these institutions to organize training courses at an early stage of the projects however when the courses were organized a certain clarity was lacking about the aims and direction of the innovations. In all three projects the training started during the curriculum development process and continued some years after the project was finished.

Unfortunately, the control of finances and purchase of new equipment was not within the control of the projects. The DoE decided about the allocation and dissemination of the new equipment and at the end of the project on electrotechnics almost all schools with an electrotechnical stream had new equipment at their disposal. In the other two projects the rate of dissemination was somewhat lower. In the project on installation technics only the four schools that were actively involved in the project, received new equipment by the end of the project. Further dissemination only took place very slowly. At the end of the project on mechanical technics only the six actively involved schools had the new equipment at their disposal although there were plans for further dissemination.

The Impact of the Projects

In the preceding sections a description was given of the course of the curriculum development and implementation process. In this section we will examine the implementation of the proposed innovations in school practice. First we will present the major results of the survey in which data were collected concerning the rate of dissemination and use of the curriculum materials (including the model curriculum, exemplary instructional materials and new equipment). Next we will look at the way 
in which the proposed innovations are implemented by teachers, and under what conditions.

Dissemination of the curriculum materials

Most of the schools that answered the questionnaire have the model curriculum at their disposal (from $79 \%$ of the schools with a division of mechanical technics up to $83 \%$ of the schools with a division of installation technics and $94 \%$ of the schools with a division of electrotechnics) ${ }^{10}$.

Table 4 shows to what extent the schools have instructional materials that are adapted to innovations proposed in the model curriculum.

Table 4: Availability of Instructional Materials Adapted to the Model Curriculum

$\begin{array}{llll} & \text { ET } & \text { IT } & \text { MT } \\ \text { number of schools } & 128 & 54 & 153 \\ & \% & \% & \% \\ \text { complete } & 38 & 7 & 3 \\ \text { incomplete } & 45 & 52 & 41 \\ \text { none } & 11 & 32 & 42 \\ \text { not answered } & 6 & 9 & 14 \\ \text { ET }=\text { project electrotechnics; } \\ \begin{array}{l}\text { IT= project installation technics; } \\ \text { MT }=\text { project mechanical technics. }\end{array}\end{array}$

Table 5: Availability of New Equipment Adapted to the Model Curriculum

$\begin{array}{llll} & \text { ET } & \text { IT } & \text { MT } \\ \text { number of schools } & 128 & 54 & 153 \\ \text { availability of } & \% & \% & \% \\ \text { new equipment } & 97 & 23 & 47 \\ \text { ET = project electrotechnics } & & & \\ \text { IT= project installation technics } & & \\ \text { MT= project mechanical technics } & & \end{array}$


Most schools have incomplete or no instructional materials adapted to the model curriculum. The relatively large percentage of schools with an electrotechnical stream that has a complete set of instructional materials, can be explained by the fact that after the conclusion of the project two teaching methods were published. One of these methods is adapted to both the instructional and the subject matter innovations proposed in the model curriculum. The second method refers only to the subject matter innovations.

The dissemination of the new equipment also shows considerable differences between the projects (see Table 5).

Almost all schools with an elcctrotechnical stream (97\%) have the new equipment at their disposal, though the dissemination rate is considerably lower with regard to the schools with a stream for mechanical technics. The conclusion can be drawn that the rate of dissemination of the curriculum materials is highest among the schools with an electrotechnical stream. Relatively few schools with a stream for installation technics as well as a stream for mechanical technics have instructional materials and new equipment at their disposal.

Implementation of the reforms

As has been mentioned, most schools have the model curriculum at their disposal. The availability of this document however does not indicate the actual use of it. Some schools have never used it, other schools did use it but do not do so any more. Reasons for this non-use are:

- the lack of new equipment;

- the lack of instructional materials;

- the limited practicability of the model curriculum

The teachers who do use the model curriculum, use it mainly as an overview of content and/or as a guide for the development of their own curriculum.

The teachers who were interviewed were asked for their opinion concerning the model curriculum. The overview of content was mentioned as the most important plus of the document for electrotechnics and mechanical technics. An important plus of the document for installation 
technics was the fit with the pupils' perception of their environment. Flaws which were mentioned were the irrelevance and the low feasibility of the proposed innovations as well as the impracticability of the documents 11 .

Following Fullan's description of the different dimensions of educational innovation $(1982 ; 1983)$ we will make, with regard to the implementation of the innovations, a distinction between the implementation of instructional innovations (i.e. new teaching strategies) and the implementation of subject matter innovations (i.e. new technologies). First we elaborate on the implementation of instructional innovations.

Most teachers who do not try (anymore) to implement instructional innovations in their teaching practice, do not have instructional material and/or new equipment at their disposal. Whether or not teachers have the model curriculum is of rather little importance with regard to the actual implementation of instructional innovations. Teachers who do implement these innovations have mentioned several prerequisites for their successful implementation. The most important of these prerequisites are:

- the availability of instructional materials;

- the availability of new equipment.

Next to these, other prerequisites are mentioned such as:

- $\quad$ training and support during the implementation process;

- a positive attitude among the teachers towards the use of new teaching strategies, and an optimum size of the class.

Also with regard to the implementation of subject matter innovations, teachers who try to implement these innovations and have incompletely adapted equipment at their disposal indicate some prerequisites for successful implementation. These prerequisites are:

- concrete instructional material accompanying the different pieces of equipment; 
- technical as well as didactical training of teachers (aimed at the use of the equipment in the classroom);

indications for the assembling of specific instruments.

When we summarize the results presented in this section it can be concluded that the two main factors that influence the degree of success of implementation of educational changes in junior technical vocational education are the availability of instructional materials and equipment that go with these innovations.

\section{Conclusions}

The results of our analysis show that in the first stages of implementation, teachers prefer concrete instructional materials including indications for the use of these materials instead of exemplary materials which they have to adapt to their own classroom situation. Recent research has shown that instructional materials, which give specified indications for their use as well as the organization of the instructional processes, have a positive influence on the implementation of innovations by helping teachers overcome the problems they face when first using new materials and/or new teaching strategies (Van den Akker, 1988). Referring to the earlier-mentioned discussion concerning the 'fidelity approach' versus the 'mutual adaptation approach' (Fullan \& Pomfret, 1979; Fullan, 1985), the results of our study show that the priority given to the 'mutual adaptation approach' in recent years does not fit in with the needs of teachers who start to implement innovations. In future curriculum innovation projects it would be worthwhile providing teachers lespecially in the first stages of implementation) with instructional materials which include detailed and elaborated indications with regard to the instructional processes and the use of the instructional materials within these processes.

It has been shown that neither the availability nor the use of the model curriculum have any influence on the implementation of either the instructional or subject matter innovations. Only teachers who have instructional materials at their disposal, that are adapted to the model curriculum, try to implement the (instructional) innovations. The relatively great attention given to the development of a model curriculum is not sufficient to meet the specific needs of teachers who try to implement educational changes. Thus we would recommend that future projects do 
not aim at the development of a model curriculum as a final product of the development process, but rather interpret this as an interim product that defines the outlines of the new curriculum in terms of objectives and teaching strategies. Based on this document the development of necessary instructional materials and equipment as well as the training of teachers can be undertaken.

The two most important factors influencing the success of implementation are the availability of instructional materials and new equipment. With regard to strategies within the three projects to provide for these two crucial conditions, the following can be concluded.

The development of a complete set of adapted and ready-made instructional materials was not realized in the projects, although in each of the projects attempts were made by teachers to develop materials. As we have stated, the specific expertise of teachers is in the field of teaching, not curriculum development or development of instructional materials. So it is questionable whether choosing teachers to develop instructional materials was the best strategy. However, if it is decided to have instructional materials developed by teachers participating in a curriculum innovation project, then it is necessary to realize that this demands a substantial amount of training to prepare the teachers for this specific task.

The availability of new equipment also facilitates the implementation of changes. With regard to this, two problems have arisen in the projects. The first problem concerns money. Although the projects had organized information-meetings and training courses during the development process, there was no clarity at all about the financial resources for the schools to purchase the new equipment. It was the DoE that at the end of the projects decided which schools would or would not receive the new equipment. The second problem concerns the attuning of the several activities within the development process. The choice and purchase of specific pieces of equipment was not made until the projects were almost finished. Therefore the correspondence between the instructional materials, part of the (technical) training courses and the chosen equipment was insufficient.

These problems can be prevented when in future curriculum innovation projects the assignment also includes clear indications with 
regard to the financial, equipment and material resources of both the development process and the new curriculum.

A coherent implementation strategy concerning just these points, is vital, together with a plan in which the different development and implementation activities are described with their interdependent relationships. In future projects such a plan should be drawn up at the beginning of the project.

Regarding these conclusions we recommend that the development of instructional material as well as the renewal of equipment should be included in the assignment for future innovation projects. Such an assignment also needs to give clarity with regard to the available budgets for the dissemination of the new equipment among schools. As stated before, the assignments for the projects referred almost only to the development of a model curriculum. Since the availability of instructional materials and equipment have been shown to be the most important factors influencing the degree of success of the implementation of innovations, it is necessary that these elements will be included in an assignment for curriculum innovation projects in the future.

In each of the projects several problems occurred with regard to the planning of the activities as well as the attuning of the different activities. Curriculum innovation is a multi-dimensional process that includes at least three dimensions: use of new materials, use of new teaching strategies and alteration of beliefs (Fullan, 1982; 1983). Although each of these dimensions which have been more or less included in the three curriculum innovation projects, coherence in activities and strategies directed at these dimensions was not sufficient. Therefore we recommend that future curriculum innovation projects develop a plan that not only describes the different strategies and activities in relationship with these dimensions of educational change, but that also pays considerable attention to the interdependent relationship between the different development and implementation activities. It also seems necessary to pay considerable attention to project management. In the three projects that were analyzed, clarity about the division of tasks and responsibilities was lacking from time to time. None of the groups within the projects was directly responsible for the monitoring of the project and/or the decision process, although the coordination team played an important role in the planning and progress of the projects. The appointment of a manager or 
management-team can prevent problems concerning planning and attuning as they arose in the three projects.

The policy implications of this study with regard to curriculum innovation projects, concern especially the assignment with which a project is started. As our conclusions have underlined, the degree of success of a curriculum innovation process is influenced by at least three factors: the availability of instructional materials, the availability of new equipment and the training of teachers. An assignment to initiate curriculum innovation should therefore include indications for these elements. It is equally necessary that the assignment should clearly state the budgetary limitations within which both the development and implementation process have to be undertaken.

\section{References}

Akker, J.J.H. van den (1988). Ontwerp en implementatie van natuuronderwijs. Lisse: Swets \& Zeitlinger.

Fullan, M. \& Pomfret, A. (1979). Research on Curriculum and Instruction Implementation. Review of Educational Research, Vol. 47, No. 1 335-397.

Fullan, M. (1982). The Meaning of Educational Change. New York/London: Teachers College Press, Columbia University.

Fullan, M. (1983). Evaluating Program Implementation: What can be Learned from Follow-Through. Curriculum Inquiry, Vol. 13, No. 2 , 215-227.

Fullan, M. (1985). Curriculum Implementation. In: Husen, T. \& Postelthwaite, T.N., (eds.). The International Encyclopaedia of Education. Oxford: Pergamon Press.

Goodlad, J.I., et al. (1979). Curriculum Enquiry, the Study of Curriculum Practice. New York: McGraw-Hill.

Josefzoon, E.O.I. (ed.). (1986). Coordinating Curriculum Policy and Practice. An AERA symposium. Enschede (Netherlands): National Institute for Curriculum Development.

Kayzel, R. \& Wel, J. van. (1984). Veranderingen in de beroepspraktijk van vakmensen en de gevolgen voor de beroepsopleidingen. Nijmegen/ Den Haag: Instituut voor Toegepaste Sociologie/Stichting voor Onderzoek van het Onderwijs. 
Leithwood, K.A. (1981). The Dimensions of Curriculum Innovation. Journal of Curriculum Studies. Vol. 3, No. 1, 25-36.

Meesterberends-Harms, G.J. et al. (1984). De onderwijskundige vormgeving van het KMBO. Haren: RION.

Miles, M.B. \& Huberman, A.M. (1984). Qualitative Data Analysis. A Sourcebook of New Methods. Beverley Hills: Sage.

Scott, W.A. (1955). Reliability of Content Analysis: The Case of Nominal Scale Coding. The Public Opinion Quarterly. 19, 321-325.

Weesie, C.A.M. \& Brummelhuis, A.C.A. ten. (1986). Een systematische werkwijze voor de analyse van kwalitatieve gegevens. In Linden, W.J. van der \& Wijnstra, J.M. (ed). Ontwikkelingen in de methodologie van het onderwijsonderzoek. Lisse: Swets \& Zeitlinger.

The Authors

JITTIE BRANDSMA works as a researcher at the Center for Applied Educational Research at the University of Twente (The Netherlands).

ALFONS TEN BRUMMELHUIS works as a researcher at the Center for Applied Educational Research at the University of Twente.

TJEERD PLOMP is a professor at the Department of Eductional Technology of the University of Twente. 


\section{Footnotes}

1. The project on electrotechnics ran for six years; from 1976 until 1982. The project on installation technics ran also for six years (1977-1983) and the project on mechanical technics had a length of five years.

2. This study was supported by a grant from SVO, the Dutch Institute for Educational Research. The commission for the study was given by the Department of Education and Science (DoE) of the Netherlands.

3. This distinction in phases within the innovation process, which is used in the comparative analysis of the three curriculum innovation projects, is based on the conceptual framework by Goodlad et al. (1979). Goodlad et al. distinguish five domains of curricula: "ideal", "formal", "perceived" "operational" and "experiential curriculum". In our study we conceive these domains as stages in the process of curriculum innovation in which curriculum forms the product or output of a specific phase as well as the input for the subsequent phase in the curriculum innovation process. We have concentrated our analysis on the first four of the above-mentioned curriculum domains. We have included the assignment given to the development agent at the start of the project as this forms the input for starting the curriculum development process. We do not distinguish the "perceived curriculum" as a separate stage, because in this study this is conceived as a factor influencing the transition from the formal to the operational curriculum.

4. The categorization of the product-indications is based on the dimensions of Leithwood's curriculum innovation (1981). These dimensions have been used in our study for the analysis of the characteristics of the different stages in the innovation process, which can also be conceived as products or as the input for a subsequent phase in the innovation process. Letthwood distinguishes nine curriculum innovation dimensions: platform, objectives, student entry behaviour, instructional materials, learner experience, teaching strategies, content, assessment tools/procedures and time. We have combined "learner experiences" and "teaching strategies" in one dimension. Firstly because these two are so much inter-related that an empirical distinction is very difficult to make. Secondly because the documents $f$ from the three projects did prove that it was almost impossible to distinguish indications or statements regarding these two dimensions from each other.

5. In the projects on installation technics and mechanical technics an ideal curriculum was developed after the assignment was formulated. These ideal curricula give a $f$ further specification of the product and process/context indications. The specification in the ideal curriculum for the project on installation technics concern primarly the characteristics of the development process (participants, tasks of the participants, basic assumptions regarding the development strategies and partial information on the financial resources for the first two years). In the ideal c curriculum for the project on mechanical technics both the product and the processindications are further specified. The product-indications not only specify the content of the model curriculum (in terms of curriculum dimensions) but mention also other products of the curriculum development process: proposals for renewal of school equipment and the training of teachers.

6. In the projects on electrotechnics and mechanical technics the SLO as well as the LPC and CITO participated. In the project on installation technics only the LPC was involved.

7. For the construction of objectives, which have been included in the model curriculum. both the educational field and business and industry have been consulted in the three projects. The main purposes of this consultation was to legitimize these objectives and to gain information about their feasibllity. 
8. The "instructional materials" which were developed in the project on electrotechnics has some years after the end of the project been used for the development of a teaching method/school books, which is now marketed by an educational publisher.

9. Fullan (1982; 1983) distinguishes three dimensions of educational change: the possible use of new or revised materials (curriculum materials/technologies); the possible use of new teaching strategies and the possible alteration of beliefs. The model curricula developed with the analyzed projects emphasize the use of new teaching strategies (and with that more or less the alteration of beliefs). The third dimension - use of new materials is rather neglected in these documents.

10. The absolute numbers of schools that co-operated in the survey were 128 (electrotechnics) 54 (installation technics) and 153 (mechanical technics). The total population consisted of respectively 244 (electrotechnics), 87 (installation technics) and 360 schools (mechanical technics). With regard to mechanical technics it is necessary to notice that at the moment the survey was executed the project was not yet finished. The schools had only a draft of the model curriculum at their disposal. After the project was finished it was possible to purchase the definitive document.

11. The characteristics of the model curriculum, judged negatively by teachers, show similarities with the characteristics of the innovation program, which Fullan (1982, 1985) identified as influencing the rate of success of educational change programs. 